\title{
EL IMAGINARIO EDUCATIVO MODERNO Y EL PROBLEMA DE LA AUTORIDAD
}

\author{
José Francisco Durán Vázquez \\ Universidad de Vigo
}

\begin{abstract}
Resumen: La autoridad ha sido un concepto muy discutido en los últimos años, especialmente en el ámbito educativo, en donde su ejercicio se ha hecho cada vez más problemático e incierto. Muchas de estas dificultades e incertidumbres tienen que ver con el contexto de las sociedades actuales. Pero también con en el propio proceso de conformación de las sociedades modernas. El texto que a continuación se presenta se detiene en una de las vertientes de ese proceso, la que se relaciona con el desarrollo del pensamiento educativo moderno. Este pensamiento ha configurado nuestra particular forma de entender la relación educativa, y también el modo en el que reflexionamos sobre ella en momentos de transformaciones y de crisis como el presente. De ahí la pertinencia de un recorrido genealógico como el que a continuación se propone.
\end{abstract}

Palabras clave: autoridad, educación, pensamiento, modernidad

\section{The imaginary modern educational and the problem of the authority}

Abstract: The authority has been a concept very discussed in the last years, specially in the educational area, where his exercise has become increasingly problematic and uncertain. Many of these difficulties and uncertainties have to see with the context of the present societies. But also with in the own process of conformation of the modern societies. The text that later one presents dwell in one of the side of this process, which relates to the development of the educational modern thought. This thought has Integrated our particular way of understanding the educational relation, and also the way in which we think about her in moments of transformations and of crisis as the present. Of there the relevancy of a genealogical route like that later he proposes.

Keywords: authority, education, thought, modernity

"El problema de la educación en el mundo moderno se centra en el hecho de que, por su propia naturaleza, no puede renunciar a la autoridad ni a la tradición, y aún así debe desarrollarse en un mundo que ya no se estructura gracias a la autoridad ni se mantiene unido gracias a la tradición" (Arendt, 2003b: 298)

No se puede evitar de ningún modo la autoridad en la educación, no es tanto (como dicen los pobres conservadores) que la autoridad parental deba mantenerse, sino que no se la puede destruir (Chesterton, 2006: 144) 


\section{INTRODUCCIÓN}

La autoridad ha sufrido un importante descrédito en el mundo moderno, hasta el punto que se ha dicho que estas sociedades ya no se estructuran en base ella (Arendt, 2003a: 145). No obstante, son también hoy cada vez más las voces que se alzan para recuperar este principio de cara a salvar la crisis en la que hoy está inmersa la esfera educativa.

El artículo que a continuación presentamos sigue el itinerario ideológico a través del cual la noción de autoridad fue cuestionada como principio clave para regular las relaciones educativas. Prestamos aquí únicamente atención a una de las caras de un proceso mucho más complejo, en el que están implicados cambios profundos en el ámbito familiar, escolar y Estatal, y también en las esferas del trabajo y del consumo; cambios sin los cuales no sería posible entender la degradación del concepto de autoridad en el ámbito educativo. Ahora bien, creemos con Max Weber (Weber, 1998) que aunque todos estos cambios forman parte de la trama socio-histórica que produjo dicho fenómeno, éste tampoco sería comprensible sin prestar atención a las ideas que en ese contexto crearon las imágenes del mundo que orientaron y legitimaron la acción humana, en este caso la acción educativa, en un determinado sentido. Es una perspectiva pues incompleta, pero imprescindible.

No nos anima en este cometido la curiosidad del arqueólogo atento a rebuscar en los orígenes por la misma esencia de su tarea, sino el interés del sociólogo por descubrir la génesis de una manera de entender la educación, que aunque en un principio fue privativa de las élites, pasó más tarde a integrar la visión del mundo del común de las gentes.

Esta actitud y esta mentalidad están presentes en muchos de los debates que en la actualidad giran alrededor del tema de la autoridad en educación, cuyo sentido más profundo nos puede ayudar a captar una perspectiva genealógica como la que aquí se propone. Dicho de otro modo, desde este punto de vista podemos comprender algunas de las paradojas que se dan en el escenario educativo actual, paradojas que se originan por la dificultad de abordar las nuevas realidades sociales con los valores y los principios que la primera modernidad había creado y consolidado.

Seguimos hoy en un escenario parecido al que Hannah Arendt había diseñado hace más de medio siglo. La pregunta sigue abierta: ¿es posible reconstruir algún tipo de autoridad en el ámbito educativo que no sea refractaria al espíritu moderno? O, planteando la misma cuestión de otro modo, ¿puede existir algún ámbito de socialización que como el educativo, por razón de sus propias características intrínsecas, quede a salvo de la influencia de los valores democráticos, sin que ello vaya en menoscabo de estos mismos valores?

Este artículo no ambiciona responder a estos interrogantes, sino repensarlos 
desde una perspectiva genealógica que dé cuenta del proceso de conformación del pensamiento educativo moderno. Situando estas preguntas en una dimensión histórica quizás estemos en mejor posición, sino para contestarlas, al menos para comprender que si se formulan de este modo y si se existen tantas dificultades para resolverlas es porque antes nos hemos acostumbrado a pensar de un determinado modo, que es el nuestro. Esta forma de pensar, su genealogía, es la que tratamos de reconstruir en el breve espacio del trabajo que a continuación se presenta.

Antes de adentrarnos en él será preciso, no obstante, mostrar qué tipo de autoridad fue la que la modernidad desterró del ámbito educativo. Sólo entonces estaremos en condiciones de comprender las razones de ese destierro. Abordemos, pues, sin más dilación esta primera materia.

\section{LA AUTORIDAD EN EL MUNDO PREMODERNO}

La autoridad es en nuestras sociedades democráticas un concepto oscuro y cargado, en la mayoría de las ocasiones, de una acepción fuertemente negativa, lo que ha contribuido a la pérdida del significado que en otras épocas estuvo asociado al mismo. Precisemos, pues, en primer lugar qué es y qué no es autoridad con el fin de salvar malos entendidos, y saber así qué es realmente lo que la memoria colectiva ha olvidado.

La autoridad implica, en primer lugar, obediencia sin discusión o violencia, pues el mismo reconocimiento de este tipo de relación por parte de quien o quienes la soportan excluye el recurso a la fuerza física, o, en el mejor de los casos, el empleo del diálogo para convencer a quien o a quienes debieran estar ya convencidos. En segundo lugar, la autoridad presupone jerarquía y desigualdad legítimamente admitidas tanto por los que obedecen como por los que mandan, y por ello está alejada tanto de las relaciones esencialmente igualitarias basadas en la argumentación persuasiva (Arendt, 2003: 147, Kojève, 2005: 36 y ss), como de aquellas otras que descansan en el mero poder coercitivo. En suma, la autoridad comporta jerarquía y legitimidad, es decir, obediencia aceptada, por lo que no necesita recurrir al uso de la fuerza o a la persuasión argumentativa para manifestarse. Desde este punto de vista, se puede decir que la autoridad es un fenómeno eminentemente social, por cuanto implica a personas que reconocen mutuamente sus vínculos recíprocos (Kojève, 2005: 36 y ss; D’Allonnes, 2008: 24).

Este concepto de autoridad es de origen romano1. Los romanos diferenciaron, como se sabe, la autoridad del poder, la potestas de la auctoritas. Quienes tenían autoridad solían carecer de poder y viceversa. Las personas con autoridad tenían la capacidad de sancionar con sus opiniones las distintas decisiones, confiriéndoles así un carácter casi sagrado que las hacía respetables y, por tanto, necesariamente acatables. Por eso se ha dicho que para los romanos la autoridad era menos que una orden y más que un simple consejo (D'Allonnes, 2008: 28-29). Por el contrario, quienes tenían poder poseían la fuerza para ejecutar aquellas decisiones, pero carecían de la capacidad necesaria para convertirlas en incuestionables.

La autoridad así entendida estaba para los romanos unida a la tradición, y la 
tradición al pasado, a la idea de fundación, es decir, al hecho de que hubo un comienzo, representado por la fundación de Roma- ab urbe condita- que daba sentido y orientaba la historia subsiguiente (Arendt, 2003a: 193-94). Este acontecimiento originario tenía una dimensión trascendente en la medida en que se situaba por encima de toda temporalidad histórica, a la que sin embargo daba origen e instituía, remitiéndola permanentemente a aquel principio fundacional al que se sometían todas las voluntades humanas (D'Allonnes, 2008: 73). Las personas con autoridad tenían que dar continuidad y profundizar en esta tradición, manteniéndola viva para las futuras generaciones2.

Ahora bien, que la autoridad permaneciese vinculada a la tradición no significaba de ningún modo que estuviese atada a ella como una copia a su modelo; por el contrario, la tradición fue entendida por los romanos como la fuente a partir de la cual había que indagar y profundizar en la realidad presente con el propósito de mejorarla. De este modo, uniendo el pasado con el presente y el futuro, los romanos no sólo idearon el modo de escapar a la fragilidad, a la mutabilidad y a la contingencia de los asuntos humanos, otorgándoles un carácter duradero e inmortal, sino también de afrontar estos asuntos con la mirada puesta en el futuro.

En un mundo así conformado, la infancia y la juventud eran meras etapas en un camino cuya meta final era la plena integración en una misma tradición representada por el mundo adulto (Neraudeau, 1984: 398-99). Esta era la responsabilidad de los mayores, que pretendían no sólo que los más jóvenes incorporasen y recreasen esa tradición, sino también que, llegado el caso, tratasen de mejorarla.

Después de la caída del Imperio Romano, esta noción de autoridad y de tradición continuó a través de la herencia que recogió e incorporó la Iglesia Cristiana, al vincular ambos conceptos a otra fundación, constituida en este caso a partir del nacimiento y resurrección de Cristo3 (Arendt, 2003a: 199). Hasta la llegada de la Época Moderna, la experiencia de los seres humanos se configuró a partir de ambos principios dando sentido y continuidad al mundo. A partir de este momento, emergerá un orden social que se va a pretender autofundado a partir de otras ideas y de otros valores que ya no serán los de la tradición ni los del pasado. En este contexto la idea de autoridad y de tradición irán perdiendo fuerza. A continuación seguiremos la dinámica de este proceso por lo que se refiere a la mentalidad educativa.

\section{EL ESCENARIO SOCIAL DEL NUEVO PENSAMIENTO EDUCATIVO}

El cambio de mentalidad con respecto a la educación comienza a percibirse en los albores de la modernidad, entre los siglos XVI y XVII, en un contexto social presidido por grandes mutaciones en los campos de la política- desarrollo del Estado Moderno-, de la filosofía y de la ciencia- pensamiento cartesiano y Ciencia Moderna-, y de la religión- Reforma y Contrarreforma. Todos estos acontecimientos actuaron en la misma dirección, socavando la creencia en la autoridad y en la tradición, y promoviendo nuevas formas de pensamiento centradas en el individuo, en la razón y en la experimentación, que rompían claramente con el pasado y con la religión, antes fuente de autoridad, para 
abrirse a un futuro lleno de promesas individuales y colectivas.

No obstante, en un principio estas transformaciones sólo afectaron a una pequeña élite, mientras que la mayoría de la población permaneció ocupada en las actividades de siempre, manteniendo unos mismos valores que extraían del pasado sancionado por la religión todo su sentido. Habrá que esperar al siglo XX para que esta población incorporase también los modos de pensamiento que habían ido conformándose a lo largo de la Época Moderna.

¿Cómo influyeron cada uno de los hechos antes citados en la nueva mentalidad, y en particular en la que se refiere a la educación de los niños?

El Estado Moderno tuvo un papel preponderante en este sentido al promover formas de sociabilidad, expresión de un nuevo ideal de civilidad vinculado a la nobleza cortesana (Elías, 1993: 115 y ss). Estas prácticas y estas actitudes serán incorporadas por los Humanistas y por las instituciones religiosas, en especial por los Jesuitas, en el contexto de la Contrarreforma. Emergerá así una nueva concepción de la infancia civilizada centrada en el niño con pretensiones racionalistas y universalistas, cuna de la moderna pedagogía, que servirá como modelo para la educación de los hijos de la nobleza y de la burguesía (Varela-Álvarez Uría, 1991: 66-67),

La Reforma Protestante creó un nuevo ethos profesional vinculado al trabajo, en un principio medio de salvación individual (Weber, 1998), y más tarde, después de la Revolución Industrial, principal actividad a partir de la cual será valorado todo mérito individual con independencia de cualquier factor relacionado con la tradición o con la herencia. La educación así entendida tendrá un fin espiritual y utilitario centrado en la transformación del yo y de la naturaleza. Se hundirán así progresivamente las bases colectivas que en la época anterior habían sustentado la noción de autoridad.

La Ciencia Moderna y el pensamiento cartesiano, por su parte, colaboraron en la misma dirección al cuestionar la noción anterior de verdad como algo revelado, como una realidad susceptible de ser captada con la única ayuda de la razón y de los sentidos, para establecer que sólo mediante la razón introspectiva y la experiencia científica los hombres podían aproximarse a la verdad del mundo. La nueva verdad se situaba así fuera del mundo de las experiencias y de las opiniones humanas, para vincularse a la esfera de una mente humana racional "en juego consigo misma", puesta a prueba a través de la experimentación científica (Arendt, 1998: 301 y ss). De esta nueva concepción de desprenderán dos importantes consecuencias. Por un lado, será cuestionado todo el corpus de tradiciones y de creencias que no estuvieran fundamentadas científica y racionalmente. Por el otro, la aproximación a la nueva verdad ya no dependía del sentido común, de la introducción en la densidad de un mundo compartido, introducción que necesariamente había de ser gradual y de la mano de los adultos, sino de un proceso lógico que, con el método adecuado, podía ser aprehendido por la razón humana desde la más tierna infancia.

En este marco así descrito se desarrollará progresivamente una nueva forma de pensar la educación en la que se excluirá finalmente la autoridad como principio legítimo. Éste fue un proceso gradual que tuvo lugar a lo largo de la Época Moderna, y cuyos principales momentos pasamos a relatar a continuación. 


\section{EL DESARROLLO DEL IMAGINARIO EDUCATIVO MODERNO Y LA EROSIÓN DE LA NOCIÓN DE AUTORIDAD}

La primera etapa de este proceso coincidió, desde nuestro punto de vista, con la emergencia del pensamiento Humanista en el contexto del nacimiento del Estado Moderno y del movimiento de la Contrarreforma. Este pensamiento sentó las bases de una pedagogía al servicio de un nuevo ideal de civilidad y de un nuevo espíritu cristiano cuyo centro de interés era el niño, aunque los modelos a imitar fuesen las formas de vida aristocrática ornadas por una cultura inspirada en la antigüedad clásica (Garin, 1987: 173; Durkheim, 1992: 239). En este mundo, expresión de la vida del hombre noble y culto, y por extensión de lo que se consideraba que tenía de más esencial y elevado el ser humano, es en el que los adultos, provistos de la autoridad que esta tradición les confería, debían educar a los más jóvenes. Desde este punto de vista, aunque el niño fuese el principal centro de atención, el adulto era el orden y la medida de todo lo que se enseñaba4.

Este modo de entender la educación apegada todavía a la tradición, contenía sin embargo numerosos elementos que sentarán las bases de lo que será más tarde la pedagogía moderna. Entre ellos podemos citar la confianza que tenían los Humanistas en la bondad y en la perfectibilidad de la naturaleza humana; naturaleza que el educador deberá motivar y suscitar suavemente mediante la razón, desarrollando así todas sus potencialidades (Garin, 1987: 145 y 78). Nace así un modelo educativo que anticipa a pedagogos como Rousseau o Pestalozzi (Huizinga, 1987: 328), modelo que aunque cuenta con la tradición para ser transmitida, se situará gradualmente del lado del niño, que se convertirá en el auténtico protagonista de la acción educativa.

No obstante, la corriente humanista, en la medida en que quiso integrar esta concepción positiva de la naturaleza humana en el mundo de la civilidad cortesana, impidió la erosión definitiva de la tradición y de las formas de autoridad que en ésta reposaban.

Esta erosión fue la que más tarde se desencadenó con el surgimiento de la pedagogía moderna, cuyos principales fundamentos pueden encontrarse ya en la obra de Comenius (1592-1670). Aquél equilibrio entre el sujeto y el mundo, que aún se mantenía en el Humanismo, se romperá definitivamente a partir de ahora. Se sigue queriendo educar a la humanidad entera, "que todos aprendan todas las cosas"; más con espíritu científico- "mediante la demostración sensual y racional"-, y con una finalidad fundamentalmente utilitaria: "Ias escuelas no serán sino talleres destinados a los trabajos" (Comenius, 1976: 8587 y 116). Ya no se tratará, pues, de incorporar a los más jóvenes a una tradición y a un saber que a ellos les precede, y que correspondía transmitir a los adultos. La fuente del nuevo saber, del que pertenece al mundo de las cosas físicas y naturales, estará por el contrario en uno mismo, en la propia mente, y no en el mundo externo. "¿Por qué hemos de utilizar los ojos ajenos mejor que los nuestros propios"- escribe Comenius- "Que el hombre se guíe por su propia razón, (y) no por la ajena" (Comenius, 1976: 86 y 41). Para educar a la infancia bastará por ello con disponer "del tiempo, los objetos y el método". Un método inspirado en la propia naturaleza, pues "el arte", también el de la enseñanza, "nada puede si no imita a la naturaleza" (Comenius, 1976: 
51-52). Dejemos, pues, que "todas las cosas fácilmente se lleven adonde la naturaleza las inclina" (...), "sin castigos ni rigor, leve y suavemente, sin coacción alguna..." (Comenius, 1976: 43-41).

Si actuando de este modo la disciplina tiene todavía un sentido, no es tanto por "externa urbanidad", como pensaban los Humanistas, sino por la necesidad de reprimir la "disposición interna y externa de nuestras pasiones" (Citado en Capitán Díaz, 1984: 486-487). Se trata de una disciplina que, sin embargo, comienza y termina en uno mismo. La disciplina del protestante encaminada a lograr el dominio espiritual del yo, y no la del católico humanista, más atento a poner en relación al sujeto con el mundo. "Cristo aparta del mundo", nos dice Comenius; "ellos-los autores clásicos que sirven de ejemplo a los Humanistassumergen más en él" (Comenius, 1976: 150).

De este modo, la obra de Comenius, influida por la mentalidad protestante y por el nuevo espíritu científico, supuso un importante cuestionamiento de la autoridad y de la tradición. En primer lugar, porque cosificó el mundo de la tradición en el que aquella autoridad se apoyaba con fines científicos y utilitarios. La autoridad pasó así del mundo a la ciencia. En segundo lugar, debido a que este mundo cosificado se convirtió en una experiencia puramente subjetiva, tanto con fines espirituales como utilitarios. No es de extrañar que en estas circunstancias las fuentes de la autoridad se fuesen agotando.

En este proceso de erosión de la autoridad la obra de John Locke (1632-1704) tuvo un papel notable. No obstante, su pensamiento se desarrolló en un contexto social que aún era en buena medida estamental. Todo ello explica que encontremos en sus escritos al lado de una mentalidad racionalista que confiaba en las potencialidades del niño, otra más preocupada por inculcarle los valores y las actitudes del noble caballero.

Desde el primer punto de vista, los postulados educativos de Locke son claramente racionalistas y empiristas. Conforme a ellos, parte de una naturaleza humana buena y racional, no contaminada por ninguna costumbre o idea previa5, en la que es posible introducir de forma lúdica y amablemente cualquier idea o conducta. De aquí se extraen varias consecuencias. Primera, frente a la bondad natural del ser humano, la maldad que en él se encuentra es de origen social (Locke, 1982: 223-224). Habrá por tanto que afirmar la naturaleza frente al mundo.

Segunda, como la naturaleza de cada niño es potencialmente inteligente y buena, no habrá necesidad de forzarla, sino saber únicamente "en qué sentido se inclina la estructura natural de su espíritu", para conducir el estudio como un "juego" o como un "recreo" (Locke, 1982: 176 y 281)

Tercera, para llevar a cabo dicha tarea el único método realmente eficaz es el racional. Por ello Locke aconseja: "Acostumbrad al niño desde muy temprano a consultar con su razón” (Locke, 1982: 192).

Cada uno de estos tres principios conllevaba un cuestionamiento de la noción de autoridad, desde el momento en que la relación educativa era pensada más en función de la naturaleza actual del niño y de sus potencialidades futuras, que de los conocimientos y normas del mundo adulto.

Sí en este contexto encuentra Locke algún motivo para emplear la autoridad en la educación de los niños, se deriva más de la necesidad de garantizar su 
libertad y su autonomía, que de un derecho que los padres o los educadores tengan previamente reconocido (Rénaut, 2002: 223). "Es más un privilegio de los hijos y un deber de los padres que una prerrogativa del poder paternal" (Locke, 2006: 87). Por lo que dicha autoridad desaparecerá tan pronto como los infantes sean capaces de razonar por ellos mismos (Locke, 2006: 80).

Ahora bien, junto a esta concepción de la educación tan apegada a la racionalidad del niño, aparece en los escritos de Locke otra más atenta a introducir a éste en el mundo nobiliar y cristiano, sinónimo todavía de civilización y de alta cultura. En este contexto la autoridad se justifica por la necesidad que tienen los padres de refrenar los impulsos naturales de sus hijos cuando éstos portan aún la mancha del pecado original. El niño deja de ser así un ser imperfecto por la acción civilizatoria de los adultos (Rénaut, 2002: 261). Resta aún, sin embargo, que éste conozca "el mundo tal y como es antes de que entre en él definitivamente" (...) (Locke, 1982: 163). Se trata de formar al hombre y al caballero antes que al profesional, para lo cual se requiere inculcar "hábitos y buenas costumbres" más que conocimientos prácticos y técnicos. Una vez esto se haya conseguido, "la instrucción", la ciencia de las cosas, "puede ser adquirida por añadidura...por medio de métodos que es sencillo imaginar" (Locke, 1982: 281). Educación, pues, mas que instrucción, porque capacita al hombre para gobernarse y ser reconocido entre sus semejantes. "Sin la virtud, sin la ciencia del mundo, sin la urbanidad,- nos dice Locke al respecto- en ninguna parte de la tierra podrá encontrarse el hombre cabal y digno de estima" (Locke, 1982: 167). Es más, "esta sola perfección le abre más ampliamente el camino del éxito, le procura más amigos y le empuja más lejos en el mundo que todas las expresiones técnicas o todos los conocimientos positivos..." (Locke, 1982: 160).

Desde esta perspectiva no se ve, pues, voluntad de remitirse a la particular naturaleza del niño. No es él quien gobierna la acción educativa. Por encima de él hay un mundo, representado por los adultos- en este caso por los miembros de una naciente burguesía cuyo modelo de comportamiento todavía es el hombre cortés y civilizado- al que éste tendrá que plegarse para ser respetado y reconocido. Los padres y los preceptores serán los autorizados para trasladar este legado a los niños (Locke, 1982: 167 y ss).

En la concepción lockeana conviven así dos modelos educativos, uno apegado aún a la tradición; el otro más vinculado a la ideología moderna, que habíamos visto ya anunciada en Comenius. Por una parte, el fin de la educación es el niño, al que hay que liberar de las perversiones de la sociedad siguiendo su naturaleza más primitiva, de forma que aprenda por su propia práctica, a través de métodos fáciles y sencillos. Por la otra, la educación se encamina a formar al hombre, dotando al niño de los hábitos y las costumbres que conforman la ciencia del mundo. Por un lado, se fomenta la autonomía del niño. Por el otro su incursión en un mundo que indudablemente le transciende. A partir de este momento el pensamiento educativo moderno concederá un mayor protagonismo al niño, que irá retirándose cada vez más de los espacios de interacción colectiva para ingresar en una esfera más íntima, autónoma y personal (Rénaut, 2002: 262). Será este un proceso que tendrá lugar en paralelo con el desarrollo y consolidación de las sociedades modernas, y que desencadenará un progresivo deterioro de la noción de autoridad en el ámbito educativo. 
La obra de Jean Jacques Rousseau (1712-1778) representó un hito dentro de este proceso porque situó al niño definitivamente en el centro de la escena educativa. Sus escritos tendrán una influencia capital en las principales corrientes pedagógicas modernas, tales como la Escuela Nueva y la Escuela comprensiva, y también en el liberalismo y en el socialismo, las dos principales ideologías que articularán la visión moderna del mundo.

Al igual que Locke, Rousseau también pretendió crear un modelo educativo libre de todo artificio social, simple y sencillo, inspirado en los dictados de una naturaleza sabia y buena. "Observad la naturaleza y seguid la ruta que os marca", fue una de las máximas principales de su credo pedagógico (Rousseau, 2002: 55). Al igual que aquél también quiso que el fin de la educación fuese hacer del niño un ser autónomo y libre, capaz de razonar y experimentar por sí mismo. "Que (nuestro alumno)- escribe- no sepa nada porque se lo hayáis dicho, sino porque lo ha comprendido por sí mismo" (Rousseau, 2002: 244).

Sin embargo, a diferencia de Locke, Rousseau rechazó frontalmente las formas de socialización estamentales por considerarlas artificiales, opresivas y ridículas, y por ello contrarias a la formación de cualquier espíritu libre (Elías, 1993b: 153). Allí donde Locke quería formar al hombre introduciéndolo en el mundo de la nobleza, Rousseau, cuyo espíritu era ya plenamente burgués, proyectaba liberar al niño de toda influencia del mundo exterior, para que no se realizase sino en sí mismo, en su propia naturaleza (Rénaut, 2002: 336-37). "La infancia- escribió- tiene maneras de ver, de pensar, de sentir, que le son propias; no hay nada menos sensato que pretender sustituirlas por las nuestras". En conclusión: "Dejad que la infancia madure en los niños" (Rousseau, 2002: 120-121). El niño se convertirá así en la principal meta del proceso educativo. Si alguna realidad exterior a él hay hacia la cual éste deba orientarse, no será otra que la que surja de la acción coordinada de los diferentes talentos individuales en el seno de las respectivas ocupaciones laborales. "Formemos- afirma- una sociedad con esos diez hombres, y que cada uno se aplique para él sólo y para los otros nueve, al género de ocupación que mejor le vaya (...) He ahí el principio aparente de todas nuestras instituciones" (Rousseau, 2002: 283).

Será ésta, sin embargo, una realidad voluntaria y completamente aceptada, que no reconoce más jerarquías que aquellas que se deriven de la capacidad y el mérito que cada uno demuestre en el seno de la actividad laboral elegida. Más allá de este hecho, cualquier otro orden social será una imposición que coarta la libertad del individuo al apartarlo de su particular naturaleza (Rousseau, 2002: 282 y ss).

De este modo, la obra de Rousseau supuso un paso definitivo en el proceso de "liberación de la infancia" (Rénaut, 2002). A partir de él el niño se convertirá en el principio y el fin de la acción educativa, al que el educador tendrá que amoldarse en todo momento descubriendo los secretos que anidan en su naturaleza. Desde este momento ya no se tratará de integrar al niño en el mundo, ni siquiera de oponerlo a él. Ha emergido el mundo de la infancia con sus propias reglas y categorías, con sus propios derechos. La autoridad ha quedado borrada del pensamiento moderno.

La herencia de Rousseau fue asumida por las principales corrientes 
pedagógicas progresistas integradas tanto en el anarquismo como en las distintas fracciones ideológicas del Socialismo, desde las más revolucionarias hasta las más reformistas y democráticas (Dommaget, 1972; Dietrich, 1976). En ellas se inspiraron muchas de las reformas educativas llevadas a cabo en los países occidentales en la segunda mitad del siglo XX.

Desde la vertiente más reformista es imprescindible tener en cuenta la obra de John Dewey (1859-1952), no sólo por lo que contiene de crítica a la autoridad, sino también porque fue el artífice de la pedagogía de la Escuela Nueva, que impulsó e inspiró muchas de las reformas educativas emprendidas por los países occidentales después de la Segunda Guerra Mundial.

La obra de Dewey supuso en muchos aspectos, por lo que a la educación se refiere, una prolongación de las ideas rousseaunianas. En efecto, hay en él el mismo propósito por adaptar la educación a los intereses del niño; intereses que, según cree, no se manifiestan sino en su propia actividad práctica. "Creosostuvo- que el verdadero centro de correlación en los ramos de la escuela no son ni las ciencias, ni la literatura, ni la historia, sino las actividades del niño mismo" (Dewey, 1908: 7). Actividades que no pueden estar orientadas de otro modo, en una sociedad articulada en torno al trabajo, que al aprendizaje de las distintas actividades laborales. "....el único medio- según Dewey- de hacer al niño consciente de su herencia social" (Dewey, 1908: 8).

Si el aprendizaje se remite a la propia experiencia del educando, no es sólo porque se considere que ésta suscita los intereses del niño, sino porque se piensa asimismo que la experiencia no es acumulativa, que no se incardina en el pasado, sino que "lo que realmente se aprende en todos y cada uno de los estadios de la experiencia constituye el valor de esa experiencia" (Dewey, 1995: 73-74). Todo esto significa que no hay diferencias entre las distintas edades, que en este aspecto todas ellas, "la infancia, la juventud y la vida adulta, se hallan en el mismo nivel educativo" (Dewey, 1995: 73), por lo que el educador no estará en mejor posición que el educando para transmitir un determinado conocimiento heredado. "Mantener vivo el presente es (pues) función de la materia educativa". Un "presente (que) no es precisamente algo que viene después del pasado, y mucho menos algo producido por él". Sino "lo que es la vida dejando tras si el pasado" (Dewey, 1995: 73).

Siendo esto así, estando todas las edades en una situación parecida con relación a la praxis, y naciendo de ella los intereses y las aptitudes del educando, la educación no puede estar orientada a otros fines que no sean los de cada individuo. Todos los demás, al ser "externamente ofrecidos limitan la inteligencia porque, dándose ya preparados, tienen que ser impuestos por alguna autoridad externa a la inteligencia" (Dewey, 1995: 95). El educador, "sea éste el padre o el maestro", no estará, pues, autorizado para trasladar su mundo a sus hijos o a sus discípulos (Dewey, 1995: 99).

Si la educación parte de las inquietudes y los intereses del niño, éste se aplicará a su actividad con particular celo y denuedo; entonces "el interés y la disciplina estarán conexionados y no en oposición” (Dewey, 1995: 116), por lo que se hará innecesaria cualquier tipo de coacción externa. En ese momento no se sabrá si el aprendizaje es un juego o en verdad un trabajo (Dewey, 1995: 177).

¿Qué papel reserva, pues, Dewey a los educadores en este contexto? El de 
orientar y guiar a sus discípulos, sin que jamás sean gobernados, procurando que progresen en todo momento a través de su propia reflexión práctica6.

Cuando se incentivan la curiosidad y la iniciativa del niño a través de la propia acción práctica, cuando se "permite la libertad individual y el juego libre de las distintas capacidades e intereses...", la escuela se transformará entonces en una organización democrática (Dewey, 1995: 256-257). Ahora bien, no se conseguirá totalmente este objetivo hasta que los intereses individuales no se conjuguen con los colectivos. Hasta que "cada persona esté ocupada en algo que hace la vida de los demás más digna de ser vivida". Cuando todo esto ocurra, la educación se convertirá en una obra plenamente justa. Una obra que además "modificará gradualmente los rasgos más amplios y más recalcitrantes de la sociedad adulta" (Dewey, 1995: 266).

Dewey termina así de invertir por completo la relación jerárquica entre niños y adultos. No sólo los primeros debían aprender por sí mismos, ya que su experiencia era tan valiosa como la de aquellos, sino que la misma organización escolar será contemplada como un ejemplo de moralidad para la renovación del mundo. La escuela dejaba de ser así un espacio y un tiempo de transición a la vida madura, para devenir un auténtico laboratorio social, "una comunidad en miniatura" (Dewey, 1995: 300).

Desde el otro lado del atlántico Émile Durkheim (1858-1917) elaboró su sociología desde una perspectiva opuesta a la de Dewey. En efecto, si la filosofía de la educación de este último conllevaba un duro ataque a la autoridad al situar al niño y a su experiencia en primer plano de la escena educativa, la sociología de Durkheim supuso, por el contrario, un intento de restaurarla mediante la integración del individuo en el orden colectivo. Si aun así Durkheim merece ser mencionado dentro del proceso ideológico que condujo al declive de la autoridad es porque también él contribuyó, como luego veremos, involuntariamente a este hecho, al vincular este concepto al de la estructura de las sociedades modernas.

No obstante, su primera intención era, como antes se dijo, establecer algún tipo de autoridad que evitase la descomposición de las sociedades modernas. Dichas sociedades atravesaban en su opinión por una etapa de transición, "una de esas fases críticas" en las que "la disciplina colectiva, en su forma tradicional, había perdido su autoridad", en la que "antiguos deberes habían perdido su fuerza de imposición, sin que se viesen aún claramente y con mirada segura cuáles son nuestros nuevos deberes" (Durkheim, 2002: 99). Una etapa, en fin, en la que "la moral tradicional está quebrantada, sin que se haya formado ninguna otra que ocupe su lugar" (Durkheim, 2000: 92). Se hacía, pues, imprescindible "despertar la fe en un ideal común" en torno al cual se reuniesen los miembros de la comunidad (Durkheim, 2002: 99-100). Un ideal que mereciese el máximo respeto, y que por ello estuviese también investido de la mayor autoridad. Era necesario, en suma, crear una nueva moral.

Ahora bien, ¿Cuál había de ser el contenido de esta moral? No podía ser ya el de la religión ni el de la tradición, porque ambas realidades eran refractarias a los valores modernos. Si la nueva moral quería ejercer algún tipo de autoridad no debía, pues, "sustraerse a la discusión", no tenía que crear "ídolos a los que, por así decir, el hombre no ose levantar los ojos", y sin embargo tenía que infundir el mismo sentimiento de veneración y respeto (Durkheim, 2002: 71). 
Una moral así tenía que estar por la fuerza en íntima conexión con la experiencia del común de las gentes sin que por ello perdiese su trascendencia; tenía que emanar, en definitiva, de la misma sociedad: "Desde el momento en el que se prohíbe recurrir a ideas teológicas por encima del individuo- había afirmado Durkheim en este sentido-, no existe más que un solo ser moral, empíricamente observable, que es el que forman los individuos al asociarse, es la sociedad" (Durkheim, 2002: 75-76). Esta sociedad no podía ser otra que la industrial, cuyos valores eran los proclamados por la modernidad. La nueva moral debía conjugar así los principios del liberalismo y los del socialismo con los de la sociedad del trabajo. Su credo sería el de la ética del trabajo, el individualismo, la igualdad y la justicia social (Lukes, 1984: 155).

Nada mejor que la escuela para inculcar esta moral porque ella misma no dejaba de ser una "pequeña sociedad" (Durkheim, 2002: 97 y 128). La familia, por el contrario, estaba peor preparada para este fin por su tendencia al afecto y al particularismo (Durkheim, 2002: 126 y ss). En efecto, el medio escolar, al igual que el social y a diferencia del familiar y del grupo de iguales, reúne a sujetos que no están relacionados ni por lazos de amistad ni de consanguinidad (Durkheim, 2002: 177). Pero a semejanza de la familia y de los amigos, los congrega en un espacio tan reducido que "la conciencia del niño puede abarcarlo con facilidad". Se configura así un ámbito de relaciones personales tan estrechas y tan densas que constituirá "una preparación muy natural a los sentimientos más elevados que queremos provocar en el niño" (Durkheim, 2002: 177). Sentimientos que le comuniquen su condición de ser social, de ser dependiente de los demás. Una dependencia que lo obliga y lo domina, pero contra la que no puede luchar, porque hacerlo sería luchar contra si mismo (Durkheim, 2002: 217). Todos esos sentimientos sólo pueden prosperar viviendo al lado de los demás, por eso la escuela "no es sino el germen de la vida social" (Durkheim, 2002. 35); por eso en ella "se hace posible la enseñanza de la moral" (Durkheim, 2002: 217). Una moral que como se sabe no puede ser otra que la de la sociedad democrática e industrial.

No obstante, si la enseñanza de la moral quería ser eficaz, debía contar además con ciertas "predisposiciones" que existen en el niño, que lo capacitan para interiorizar los dictados que en aquella se contienen. Estas predisposiciones no son otras que su inclinación a seguir determinadas rutinas y su tendencia a la imitación. Por medio de ambos resortes el niño podrá ser "orientado en el sentido conveniente" (Durkheim, 2002: 122).

Ahora bien, la moral que Durkheim propone no debe descansar sólo en las rutinas, en los sentimientos y en las pasiones (Durkheim, 2002: 95). Si bien es necesario que "las reglas morales estén investidas de una autoridad", que sean experimentadas y sentidas como un deber inexcusable, "esta autoridad no debe sustraerse a la discusión" (Durkheim, 2002: 71). Hace falta, en consecuencia, que los individuos tengan "la conciencia más clara y más completa posible, de las razones de (su) conducta" (Durkheim, 2002: 110). Para ello, se precisa que la moral pueda ser "explicada" a los niños a través del currículum escolar. Que la historia pueda mostrarles, por ejemplo, "los lazos que nos atan al mundo"; o que las ciencias naturales les enseñen que no "sólo el hombre tiene que vivir en grupo" (Durkheim, 2002: 217). En fin, que cada una de esas materias les haga comprender las razones de sus sacrificios, la altura de la tarea para la que han sido reclamados. Actuando de este modo, por 
medio de la ciencia, el sometimiento a la autoridad moral deja de ser "una resignación pasiva" para transformarse en "una adhesión iluminada" (Durkheim, 2002: 107). Una adhesión que es el resultado de una obligación "libremente aceptada" (Durkheim, 2002: 110). En palabras de Durkheim, "el individuo se somete a la sociedad y esta sumisión es la condición de su liberación" (Durkheim, 2000: 96).

El maestro, como representante de la comunidad, es el que tendrá que comunicar esta moral a los niños. Para ello es indispensable "que sienta realmente en sí la autoridad que debe comunicar", que crea "en su cometido y en la grandeza de su tarea". Que tenga, en suma, una vocación derivada de la conciencia de la función que está llamado a desempeñar, y que sepa transmitirla adecuadamente a sus discípulos (Durkheim, 2002: 132).

En la medida en que esta concepción de la moral representaba la nueva trascendencia laica a la que los individuos modernos se sometían de una forma voluntaria y autoconsciente como contrapartida a futuras promesas de movilidad social, de desarrollo personal y de integración ciudadana en condiciones de igualdad formal, el proyecto durkheimiano contribuyó a crear un espacio de autoridad legítima en torno a la escuela que fue legitimado por las sociedades democráticas e industriales con posterioridad a la Segunda Guerra Mundial.

El encantamiento del que gozó este "programa institucional" (Dubet, 2006: 29 y ss) explica en buena medida la expansión de la educación de masas en la mayoría de los países occidentales después de la Segunda Guerra Mundial. Pero este encantamiento parece haberse esfumado en las últimas décadas, y también los modelos de autoridad que formaban parte de aquel programa. En efecto, en las condiciones instauradas por la tardo-modernidad en el que ya no existe consenso en torno a los ideales de la ciudadanía republicana con sus autoridades y sus disciplinas, en el que los principios meritocráticos no encuentran ya un claro reflejo en el mundo del trabajo, se ha roto la anterior armonía, que la obra de Durkheim había fundamentado y que por un momento pareció realizada, entre el sujeto y el orden colectivo. Es aquí donde afloran las debilidades del proyecto moral durkheimiano. En efecto, como la moral era una función social más de la estructura de las sociedades modernas, se revelaba como más racional, transparente y autoconsciente. No obstante, el reverso de esa funcionalidad, de esa transparencia y de esa autoconciencia era, tal como el propio Durkheim había reconocido, su tendencia a la mutabilidad (Durkheim, 2002: 102). Dicho de otro modo, tan pronto como se modificasen las necesidades funcionales de la sociedad, tan pronto como los sujetos dejasen de percibir alguna ventaja en el orden social, podría producirse una desacralización de la moral. A partir de ese momento sólo podría avanzarse en la creación de un nuevo edificio moral.

La nueva moral que ha surgido de esta situación, característica de muchas sociedades occidentales en la tardo-modernidad, reposa más en el individuo que en la colectividad. Se apoya más en el reconocimiento de la diversidad y la subjetividad infantil que en las normas colectivas, más en el sujeto que en la institución (Raynaud, 1983; Gauchet, 2002; Dubet, 2006). Ha emergido así con fuerza un discurso, heredero por otra parte del pensamiento educativo moderno, argumentado en términos psicológicos y pedagógicos, que ha 
convertido al niño y al joven en los verdaderos protagonistas del proceso educativo. En este contexto aquella noción de autoridad, que habían invocado los sistemas educativos en expansión después de la Segunda Guerra Mundial, se ha ido poco a poco desvaneciendo.

\section{CONCLUSIÓN}

Hasta aquí hemos resumido el proceso a través del cual se fue conformando el pensamiento educativo moderno en relación con el problema de la autoridad. $A$ través de este proceso se ha mostrado como a partir de un momento, previo a la modernidad, en el que la autoridad se legitimó con respecto al pasado y a la tradición, se operó un cambio profundo de mentalidad en el contexto creado por el desarrollo del Estado Moderno, la Reforma Protestante, la Nueva Ciencia y el pensamiento Cartesiano, y también por la emergencia de las sociedades industriales vertebradas por el trabajo. Este cambio consistió en el creciente protagonismo que irá cobrando el niño con relación al mundo adulto.

En un primer momento el pensamiento educativo mantuvo un cierto equilibrio entre tradición y modernidad, entre la infancia y el mundo de los adultos. Pero más tarde reaccionó frente a la tradición y se inclinó definitivamente del lado del niño, poniendo al mundo bajo sospecha. Aquél fue considerado una criatura esencialmente racional con infinitas potencialidades, en medio de una naturaleza cosificada escenario de sus propias experiencias, y fuente, además, de numerosas utilidades y riquezas. No era el niño, pues, el que tenía que plegarse ante el mundo, sino éste ante aquél.

Este pensamiento fue reelaborado más tarde por John Dewey y Émile Durkheim en el contexto de la sociedad industrial y democrática, y su influencia se dejó sentir tanto en Europa como en Norteamérica. El primero reforzó todavía más la autonomía de la infancia siguiendo en buena medida el programa rousseauniano; el segundo, en un escenario caracterizado por la crisis ocasionada por la emergencia de las sociedades industriales europeas, desarrolló un proyecto moral en el que se recuperaba de nuevo la noción de autoridad. Este proyecto, que incorporaron y legitimaron muchas democracias industriales después de la segunda Guerra Mundial, pretendía armonizar los intereses individuales con los colectivos en el seno de una sociedad democrática articulada alrededor del trabajo. $Y$ durante un tiempo, el que fue desde los años 50 a los 80 del siglo pasado, pareció que este objetivo se había alcanzado. Era un tiempo en el que la escuela gozaba de una amplia legitimidad y los docentes tenían una autoridad reconocida como representantes de ese proyecto colectivo (Dubet, 2006: 29 y ss). 
Pero ese tiempo ya ha pasado. El consenso que se había creado en torno al programa moral de posguerra ya no existe. Los principios universales de la ciudadanía, de la cultura y de la sociedad del trabajo que lo habían sustentado son cada vez más ambiguos. Los profesores y los alumnos se reconocen cada vez menos en ellos. Ya "no hay homología entre la experiencia del profesional y la del socializado" (Dubet, 2006: 383). Las instituciones son cada vez menos capaces de reconciliar los intereses individuales y los colectivos. En este marco emergen los sujetos con más fuerza moral que nunca. Sujetos que ya habían sido reificados, como se ha mostrado, por el pensamiento educativo moderno, pero que en la etapa anterior todavía encontraban su lugar en el orden disciplinario de las instituciones educativas. Con el declive de estas instituciones el alumno ha cedido su lugar al joven y al niño (Dubet, 2006: 85 y ss), centros de interés de los discursos pedagógico y psicológico, cuyos derechos son públicamente reconocidos. En este contexto la relación educativa ya no puede sustentarse como antes lo hacía en la autoridad y en la disciplina, en su lugar apela cada vez más a la motivación, al encanto y al carisma personal, volviéndose así cada vez más precaria porque ya no descansa en principios que se presuponen y que son indiscutidos, sino que ha de ser justificada en cada momento.

Se abre así en el ámbito educativo un escenario de crisis de autoridad que se traduce en numerosos desencuentros, conflictos y, en ocasiones, también en violencias. De ahí la necesidad de repensar de nuevo el problema de la autoridad, pero también la dificultad de hacerlo porque se trata de un concepto que goza de poco predicamento en el mundo moderno. Distanciémonos, sin embargo, un poco de la escena y, antes de concluir este artículo, hagámonos algunas preguntas aunque no tengan fácil respuesta:

¿En qué principios indiscutidos puede basarse hoy la autoridad? $O$, en otras palabras, ¿cuál es nuestra idea de sociedad? ¿La sociedad de mercado? ¿El mundo del consumo? ¿Qué herencia queremos transmitir los miembros adultos de nuestra sociedad a los más jóvenes?

En otro orden de cosas, ¿es posible el ejercicio de la autoridad sin jerarquías previamente admitidas?, ¿sin asumir la superioridad previa de una de las partes de la relación educativa sobre la otra? Dicho de otro modo, ¿hasta dónde la autoridad educativa es compatible con el orden democrático? Todas estas preguntas responden a las contradicciones que hoy afectan al ámbito educativo; todas ellas están enraizadas en nuestra propia herencia social, en nuestra propia manera de ver el mundo. Esperemos que el trabajo que aquí concluye haya tenido alguna utilidad para entender, al menos, por qué son formulados estos interrogantes. Sólo así se estará en disposición de profundizar en el análisis social siguiendo su estela. 


\section{BIBLIOGRAFÍA GENERAL}

(1998) ARENDT, Hannah, La condición humana, Ed. Paidós, Barcelona.

(2003a) ARENDT, Hannah, “¿Qué es la autoridad?", en ARENDT, H: Entre el pasado y el futuro, Barcelona, Península, pp. 145-225.

(2003b) ARENDT, Hannah, "¿La crisis en la educación?" en ARENDT, H: Entre el pasado y el futuro, Ed. Península, Barcelona, pp. 269-301.

(2003c) ARENDT, Hannah, "El concepto de historia: Antiguo y Moderno" en ARENDT, H: Entre el pasado y el futuro, Ed. Península, Barcelona, pp. 67-143.

(1987) ARIÉS, Philippe El niño y la vida familiar en el Antiguo Régimen, Ed. Taurus, Madrid

(2000) BÁRCENA, Fernando-MÈLICH, Joan-Carles "Hannah Arendt: Educación y natalidad", en BÁRCENA, Fernando-MĖLICH, Joan-Carles: La educación como acontecimiento ético. Natalidad, narración y hospitalidad, Ed. Paidós, Barcelona, pp. 63-90.

(2009) BÁRCENA, F "Una pedagogía del mundo. Aproximación a la filosofía de la educación de Hannah Arendt", Anthropos, 224, Barcelona, pp. 113-124.

(2007) BAUMAN, Zygmunt Los retos de la educación en la modernidad líquida, Ed. Gedisa, Barcelona

(1997) BERGER, Meter L. y LUCKMANN, Thomas Modernidad, pluralismo y crisis de sentido, Ed. Paidós, Barcelona.

(1985) BOWEN, James Historia de la Educación Occidental. (2 Vols.) Ed. Herder, Barcelona

(2004) BURCKHARDT, Jacob La cultura del Renacimiento en Italia, Ed. Akal,

Madrid

(1984) CAPITÁN DÍAZ, Alfonso Historia del pensamiento pedagógico en Europa (Vol I), Ed. Dykinson, Madrid

(1986) CAPITÁN DÍAZ, Alfonso Historia del pensamiento pedagógico en Europa (Vol II) Ed. Dykinson, Madrid.

(2006) CHESTERTON, G.K Lo que está mal en el mundo, Ed. Ciudadela, Madrid.

(2007) CLERO, JP, Qu'est-ce que l'autorité? Ed. Vrin, París

(1976) COMENIUS, Jhon Amos, Didáctica Magna, Ed. Porrúa, México.

(1985) COMPÈRE, Marie-Madeleine Du collège au Lycée (1500-1850), Ed. Gallimard, París.

(1908) DEWEY, John, Mi credo pedagógico, Ed. Revista de la Asociación de 
Educación Nacional de Santiago de Chile, Santiago de Chile.

(1929) DEWEY, J, La escuela y la sociedad, Ed. Francisco Beltrán, Madrid

(1995) DEWEY, J, Democracia y educación, Ed. Morata, Madrid.

(1976) DIETRICH, Theo, Pedagogía socialista, Ed. Sígueme, Salamanca.

(1999) DOMINGO, Rafael Auctoritas, Ed. Ariel, Barcelona.

(1972) DOMMAGET, Maurice Los grandes socialistas y la educación, Ed. Fragua, Madrid.

(2006) DUBET, François El declive de la institución. Profesiones, sujetos e individuos en la modernidad, Ed. Gedisa, Barcelona.

(2008) DURÁN VÁZQUEZ, José Francisco "La educación moral durkheimiana y la crisis de la esfera educativa en el mundo tardo-moderno", Nómadas, 17, ISSN 1578-6730, Madrid, pp. 207-220.

(1992) DURKHEIM, Émile Historia de la educación y de las doctrinas pedagógicas, Ed. La Piqueta, Madrid.

(1995a) DURKHEIM, É, El suicidio, Ed. Akal, Madrid.

(1995b) DURKHEIM, É, La división del trabajo social, Ed. Akal, Madrid.

(1996) DURKHEIM, É, Educación y sociología, Barcelona, Península.

(2000) DURKHEIM, É, Sociología y Filosofía, Madrid, Miño y Dávila.

(2002) DURKHEIM, É, La educación moral, Ed. Morata, Madrid.

(2003) DURKHEIM, É, Lecciones de Sociología, Ed. Miño y Dávila, Buenos Aires.

(1993a) ELIAS, Norbert, El proceso de civilización, Ed. FCE, Madrid.

(1993b) ELIAS, Norbert, La sociedad cortesana, Ed. FCE, Madrid

(1985) ERASMO DE ROTTERDAM, De la urbanidad en las maneras de los niños, Ed. Integraf, Madrid.

(2005) ERASMO DE ROTTERDAM, Coloquios familiares, Ed. Anthropos, Barcelona

(2006) ESPOT, María Rosa, La autoridad del profesor. Qué es la autoridad y cómo se adquiere, Ed. Praxis, Madrid.

(1990) FERNÁNDEZ ENGUITA, Mariano, La cara oculta de la escuela. Educación y trabajo en el capitalismo, Ed. SXXI, Madrid

(1978) FERRER I GUARDIA, Francisco, La escuela moderna. Póstuma explicación y alcance de la enseñanza racionalista, Ed. Tusquets, Barcelona

(1999) FOUCAULT, Michel, Vigilar y castigar, Ed. Círculo de Lectores Barcelona.

(1989) FOURIER, charles, El nuevo mundo industrial y societario, Ed. FCE Madrid.

(1987) GARIN, Eugenio, La educación en Europa, Ed. Crítica, Barcelona.

(2002) GAUCHET, Marcel «L'école à l'école d'elle-même», en GAUCHET, 
Marcel, La démocratie conte elle-même, Ed. Gallimard, París, pp. 109-169 (1987) HUIZINGA, Johan, Erasmo, Ed. Salvat, Barcelona

(2004) JACQUARD, Albert; MANENT, Pierre; RÉNAUT, Alain, Una educación sin autoridad ni sanción, Ed. Paidós, Barcelona.

(1996) JAEGER, Werner Paideia, Ed. FCE, Madrid.

(2005) KOJÈVE, Alexandre, La noción de autoridad, Ed. Nueva Visión, Buenos Aires.

(1979) LASH, Christopher, La cultura del narcisismo, Ed. Andrés Bello Barcelona.

(1999) LE GOFF, Jean-Pierre, La barabarie douce. La modernisation aveugle des entreprises et de l'école, Ed. La Découverte, París.

(1994) LIPOVETSKY, Gilles, El crepúsculo del deber, Ed. Anagrama, Barcelona.

(1980) LOCKE, John, Ensayo sobre el entendimiento humano (Vol I), Editora Nacional, Madrid.

(1982) LOCKE, J, Pensamientos sobre educación, Ed. Humanitas Madrid.

(2006) LOCKE, J Segundo Tratado sobre el Gobierno Civil, Ed. Alianza, Madrid.

(1984) LUKES, Steven Émile Durkheim, Su vida y su obra, Ed. SXXI, Madrid.

(2009) MARINA, José Antonio, La recuperación de la autoridad: Crítica de la educación permisiva y de la educación autoritaria, Ed. Versátil, Barcelona.

(1985) MARROU, Henri-Irinée, Historia de la educación en la antigüedad, Ed. Akal, Madrid.

(1998) MARSHALL, T.H, Ciudadanía y clase social, Ed. Alianza Editorial, Madrid.

(1962) MEAD, Margaret, Educación y cultura, Ed. Paidós, Buenos Aires.

(2003) MENDEL, G, Une histoire de l'autorité. Permanences et variations, Ed. La Découverte/Poche, Paris.

(1984) NERAUDAU, Jean-Pierre, Être enfant à Rome, Ed. Les Belles Lettres París.

(1963) OWEN, Robert, Textes choisies, Ed. Éditions Sociales, París.

(1967) PROUDHON, Pierre-joseph, Oeuvres choisies, Ed. Gallimard, París.

(1983) RAYNAUD, Philippe “L'esprit démocratique et la crise de l'enseignement" Le Débat, 26, pp 113-123, París

(2002) RÉNAUT, Alain, La libération des enfants, Ed. Hachette, París.

(2004) RÉNAUT, A La fin de l'autorité, Ed. Flammarion, París.

(2008) REVAULT D’ALLONNES, Myriam El poder de los comienzos. Ensayo sobre la autoridad, Ed. Amorrortu, Buenos Aires.

(1997) RICOEUR, Paul, Ideología y Utopía, Ed. Gedisa, Barcelona 
(1988) RODRIGUEZ GUERRA, Jorge, "Crisis" del estado de Bienestar y política educativa", Arbor, 514, pp 99-126, Barcelona.

(2007) RODRIGUEZ PASCUAL, Iván, Para una sociología de la infancia: aspectos teóricos y metodológicos, Ed. CIS, Madrid.

(2002) ROUSSEAU, Jean-Jacques, El Emilio, Ed. Alianza editorial, Madrid.

(2003) ROUSSEAU, J. J, Del contrato social, Ed. Alianza editorial, Madrid.

(1982) SENNETT, Richard, La autoridad, Ed. Alianza Editorial, Madrid.

(1988) SIMMEL, Georg "La moda" en SIMMEL, Georg, Sobre la aventura. Ed. Península, Barcelona, pp. 26-55

(2001) SIMMEL, G, El individuo y la libertad, Ed. Península, Barcelona.

(2004) SINGLY, F. De, Enfants-adultes: vers une égalité dde status ?, Ed. Universalis, París.

(1983) STARABINSKI, Jean, Jean-Jacques Rousseau, la transparencia y el obstáculo, Ed. Taurus, Madrid.

(2006) TAYLOR, CH, Imaginarios sociales modernos, Ed. Paidós, Barcelona.

(1996) TAYLOR, Charles, Las fuentes del yo. La constitución de la identidad moderna, Ed. Paidós, Barcelona.

(1991) VARELA, Julia-ALVAREZ URÍA, Fernando, Arqueología de la escuela, Ed. La Piqueta, Madrid.

(1991) VARELA, Julia, "EI triunfo de las pedagogías psicológicas", Cuadernos de Pedagogía, 198, Madrid, pp. 56-58

(2004) VIGARELLO, G, Le corps redressé. Histoire du pouvoir pédagogique, Ed. Armand Colin, París.

(1998) WEBER, Max, "La ética protestante y el espíritu del capitalismo" en: WEBER, M, Ensayos sobre sociología de la religión, (Vol I), Ed. Taurus, Madrid, pp. 25-202 
NOTAS

${ }^{1}$ Los griegos desconocieron, sin embargo, el sentido político de dicho término, por lo que no aparece en lengua griega antigua una palabra equivalente a la romana con un significado semejante (Domingo, 1999: 14; Arendt, 2003a: 164). Tal es así que el historiador griego Dión Casio al escribir su historia de Roma no pudo hallar un vocablo griego que diese cuenta del significado de la palabra romana autorictas (Arendt, 2003a: 164-65)

${ }^{2}$ como se ha dicho, la palabra autorictas procede del verbo augere, que significa aumentar, en el sentido de prolongar el hecho fundacional, la tradición, profundizando en ella

${ }^{3}$ El Papa Gelasio afirmaba en el siglo V que "principalmente, hay dos cosas (...) que gobiernan este mundo: la autoridad sagrada de los pontífices y el poder real" (Citado en D'Allonnes, 2008: 37)

${ }^{4}$ Resulta relevante a este respecto que los tratados educativos de Erasmo, de muy amplia difusión en su época, utilizasen un lenguaje y unos ejemplos extraídos de la vida adulta que un lector de hoy juzgaría inapropiados para los niños (Erasmo, 1985 y 2005)

${ }^{5}$ El punto de vista de Locke sobre la educación se basa en su teoría del conocimiento, en virtud de la cual considerará que, siendo la infancia una etapa en la que todavía no se han gravado costumbres y hábitos, en la que todavía no hay ideas innatas- teoría empirista de la tabula rasa-, se puede, siguiendo los métodos de una educación racional, conseguir todo lo que se quiera (Locke, 1980)

${ }^{6}$ En consonancia con estas ideas Dewey llegó incluso a proponer un cambio en la estructura física de las aulas. Sacó los pupitres y situó en su lugar bancos de laboratorio. Eliminó la mesa del profesor e invitó a los alumnos a que permaneciesen de pie discutiendo sobre cuestiones relacionadas con la vida material (Bowen, 1985: II, 532) 